\title{
PEMETAAN RAGAM HIAS ACEH DALAM KAJIAN GEOGRAFI BUDAYA DAN ETNOGRAFI
}

\author{
T. Junaidi ${ }^{1}$, Mufti Riyani ${ }^{2}$ \\ Program Studi Pendidikan Sejarah FKIP Universitas Samudra \\ Jln. Meurandeh - Kota Langsa Provinsi Aceh \\ *Email: revolusihening@ rocketmail.com
}

\begin{abstract}
Ornament is a symbol of cultural identity in a society that is in tune with the essence as homo symbolicus. The process spawned a culture in the development of decoration that is specific typical by region or culture. This study intends to acquire mapping in order to facilitate the identification of decorative ornamentation Acehnese, because in creative economy industry appears uniform and does not address the real wealth Aceh. Mapping the typical decorative loacl region these cultures can be analyzed based on the study of geographical and ethnographic analysis that refers to a system of understanding of space and time which embraced the people of Aceh. This study utilizes ethnographic methods to move select projects ethnography, collecting ethnographic data, creation of ethnographic recordings, analysis and writing ethnography. The result showed that the outline of decorative Aceh can be divided into pattern Aceh East Coast, West Coast and Interior Styling Aceh. This study is expected to be the conservation of the wealth of decorative Aceh so can be used in a variety of media culture in the future.
\end{abstract}

Keywords: Ethnography, Cultural Geography, Mapping, Decoration.

\section{PENDAHULUAN}

Aceh merupakan suatu kesatuan masyarakat yang unik. Perjalanan sejarah menempa Aceh sebagai suatu wilayah yang memiliki ciri khusus secara eksis mampu menampilkan identitasnya dibumi nusantara. Berdasarkan sisi pola dasar bahasa dan sosial, Aceh termasuk masyarakat Sumatra dan Asia Tenggara. Namun memiliki ciri khusus berupa budaya yang muncul dari kerajaan pantai yang dibentuk selama 4 abad yang menangkal dominasi asing. Ingatan mengenai kejayaan kebudayaan Aceh masih jelas membekas hingga abad ke 20 sehingga identitas Aceh memiliki daya imunitas yang baik. Jika wilayah di luar Aceh banyak menyerap konsep modern negara dari kolonialisme Barat atau Hindia Belanda. Identitas unik rakyat Aceh salah satunya diwujudkan dalam bentuk ragam hias yang dilambangkan oleh sembilan lipat cap kerajaan (cap sikureueng) dan juga muncul dalam kisahkisah dan syair-syair kepahlawanan (Reid, 2011:336).
Wilayah pengaruh kebudayaan Aceh menurut William Marsden banyak dipengaruhi oleh kekuatan politis semasa kerajaan Aceh. Wilayah tersebut berbatasan dengan Batak, bergerak ke arah pedalaman tidak lebih dari 50 mil ke tenggara. Tahun 1778 daerah Aceh meliputi Pidie, Samalanga dan Pasai di pesisir Utara dan Timur, sedang di pesisir barat pada masa lalu mencapai Indrapura dan Tiku, sementara saat ini wilayahnya hanya sampai Barus. Penduduk Aceh saat ini dibedakan menjadi wilayah Allas, Riah dan Karrau. Tata krama orang Aceh dipakai oleh dua suku yaitu Allas dan Riah sedangkan Suku Karrau mengikuti adat Batak. Karrau secara geografis lebih dekat dengan Batak dan hanya dipisahkan oleh pegunungan (Marsden, 2008: 365-366).

Wilayah-wilayah kebudayaan Aceh dapat diklasifikasikan secara garis besar menjadi wilayah kebudayaan dengan corak kebudayaan masyarakat peladang dan wilayah kebudayaan dengan corak masyarakat nelayan. Kelompok kebudayaan peladang biasanya hidup di daerah hutan dan dataran tinggi yang memungkin mereka dalam aktifitasnya sebagai masyarakat 
peladang. Kelompok kebudayaan yang berikutnya adalah kelompok kebudayaan nelayan. Kelompok kebudayaan ini hidup di sepanjang pantai dan desa-desa penyangga dengan berbagai tipe masyarakat pantai. Desadesa nelayan umumnya terdapat di daerah muara sungai atau teluk namun pada tipe tertentu tidak menutup kemungkinan terdapat desa-desa penyedia bahan pangan yang masuk dalam mandala budaya masyarakat nelayan. Kebudayaan nelayan ditandai kemampuan teknologi pembuatan kapal, pengetahuan caracara berlayar di laut, pembagian kerja nelayan laut.

Masyarakat pada mandala budaya tersebut memiliki kekayaan budaya yang menampilkan ciri khasnya masing-masing. Salah satu ciri khas budaya yang masif digunakan untuk menunjukan identitas suatu budaya adalah ragam hias. Ragam hias disebut juga ornamen, merupakan salah satu bentuk karya seni rupa yang telah berkembang sejak masa prasejarah khususnya mencapai puncak pada zaman neolitikum.

Ragam hias dalam aplikasinya pada bidang hias dapat distilisasi (stilir atau digubah) sehingga bentuknya dapat sangat bervariasi. Namun proses stilisasi ini tidak terlepas dari bentuk dasar pembentuk ragam hias yang disebut motif. Motif adalah unsur pokok suatu ragam hias yang menjadi penciri suatu identitas budaya. Sunaryo, A. dkk (2009:14) menyebutkan:

"motif merupakan unsur pokok sebuah ornamen. Melalui motif, tema atau ide dasar sebuah ornamen dapat dikendalikan, sebab perwujudan motif pada umumnya merupakan gubahan atas bentuk-bentuk di alam atau perwujudan representasi alam yang kasatmata. Akan tetapai ada pula yang merupakan hasil khayalan semata, karena bersifat imajinatif bahkan tidak dapat dikenali kembali, gubahan-gubahan motif kemudian disebut bentuk abstrak"

Berdasarkan kutipan diatas, gubahangubahan memang sangat dimungkinkan akan tetapi bentuk dasar motif atau biasa disebut dengan motif dasar merupakan identitas penciri yang mengejawantahkan ide-ide masyarakat pendukungnya. Kurangnya pemahaman masyarakat pewaris budaya terhadap ide-ide tersebut menyebabkan gubahan-gubahan yang dilakukan merupakan tindakan tanpa dasar dan mengaburkan keunikan identitas masing-masing mandala budaya. Oleh sebab itu, pemetaan ragam hias Aceh dengan menggali motif-motif dasar pada masing-masing wilayah di Aceh dengan pendekatan geografis dan etnografis penting untuk dilakukan.

\section{METODE PENELITIAN}

Pendekatan penelitian yang digunakan adalah penelitian lapangan etnografi yang bersifat holistik-integratif, thick description. analisa kualitatif dalam rangka mendapatkan native's point of view (Spradley, 2007) dimanfaatkan untuk mengintepretasi data.

Sumber data terdiri dari sumber data budaya. Sumber tersebut dapat ditelusuri melalui benda-benda budaya sebagai peninggalan di masa lalu. Selain itu, sumber data budaya dapat diperoleh dari pelaku budaya yakni para informan sebagai subyek penelitian.

Pengumpulan data dilakukan melalui pengamatan berpartisipasi, wawancara mendalam dengan para informan dan dokumentasi khususnya pada dokumen etnografi. Pengamatan berpartisipasi dilakukan dengan cara keterlibatan peneliti di dalam proses penelitian. Wawancara dilakukan secara tidak terstruktur dan informal dalam berbagai situasi.

Alur penelitian yang digunakan dalam penelitian ini mengacu pada alur penelitian etnografi (Spradley dalam Creswell, 2012:475) dengan langkah metode sejarah:

1. Pemilihan suatu proyek etnografi melalui studi pendahuluan. Siklus ini dimulai dengan memilih suatu proyek penelitian etnografi dengan mempertimbangkan ruang lingkup penelitian.

2. Pengumpulan data etnografi dilakukan dengan melakukan kajian budaya pada masyarakat Aceh.

3. pembuatan rekaman etnografi.

4. Intepretasi data dan Analisis data etnografi.

5. penulisan etnografi.

\section{HASIL DAN PEMBAHASAN}

Pemetaan ragam hias akan lebih mudah dipahami dengan pengelompokan sifat dan motif dasar pada masing-masing wilayah. 
Sebelum menemukan pemetaan ragam hias masyarakat Aceh. Kita dapat mengelompokan sifat geografi Budaya pada masyarakat Aceh yang secara etnografi tersusun atas masyarakat peladang dan masyarakat nelayan. Penelitian ini menghasilkan pemetaan terhadap wilayah Aceh sebagai wilayah dengan karakteristik masyarakat Nelayan dan Masyarakat Peladang, meskipun beberapa wilayah memiliki identitas ganda atau bersifat percampuran diantara keduanya.

Berdasarkan data penelitian, dapat diketahui beberapa kabupaten/wilayah di Aceh yang menjadi perwakilan representasi motif hias ornamentik khas Aceh. Dokumen yang dimaksud ditemukan oleh peneliti dirumah salah satu narasumber (Ibu Mariana, Desa Ulee Madoon, Aceh Utara dengan kondisi tanpa penerbit dan penulis; dimungkinkan adalah dokumen dekranasda Provinsi Aceh dengan judul Motif Hias Seni Ornamentik Aceh yang disusun tahun 2002, sebelum peristiwa Tsunami).

Dokumen tersebut menunjukan bahwa beberapa Kabupaten di Aceh seperti; Kabupaten Aceh Besar, Kabupaten Pidie, kabupaten Aceh Utara, Kabupaten Aceh Timur, Kabupaten Aceh Tengah, kabupaten Aceh Barat, Kabupaten Aceh Selatan dan Kabupaten Aceh Tenggara merupakan daerah-daerah di Aceh yang memiliki motif hias ornamentik yang khas. Motif hias ornamentik tersebut dikembangkan dari motif dasar khas daerah yang bersangkutan. Namun demikian ada beberapa wilayah yang mengembangkan ragam hias dengan motif dasar yang sama.

Motif dasar Aceh Besar merupakan motif dasar yang banyak dimanfaatkan dibeberapa daerah lainnya meliputi wilayah Pidie, Aceh Utara dan Aceh Timur. Sedangkan Aceh Tengah, Aceh Barat, Aceh Selatan dan Aceh Tenggara memiliki motif dasarnya tersendiri, meskipun beberapa memiliki motif dasar sama dengan penamaan yang berbeda atau nma yang sama dengan bentuk yang berbeda.

Motif-motif dasar pada kabupaten Aceh Besar terdiri dari motif gigo darut (gigi belalang), pucuk reubong, oun (daun), oun labu (daun labu), oun ubi (daun ubi), bungong kepula (tanjung), bungoung jeumpa, bungoung seulanga, bungong meulu (bunga melur), puta talo (putar tali), bah aneuh (buah nanas), sisik naga, oun paku (daun paku), talo ie (tali air), bulan bintang, awan meucanek (awan beriring), talo meuputa, rante, bungong ek leuk. Berikut adalah sketsa masing- masing motif dasar tersebut (Gambar 1).

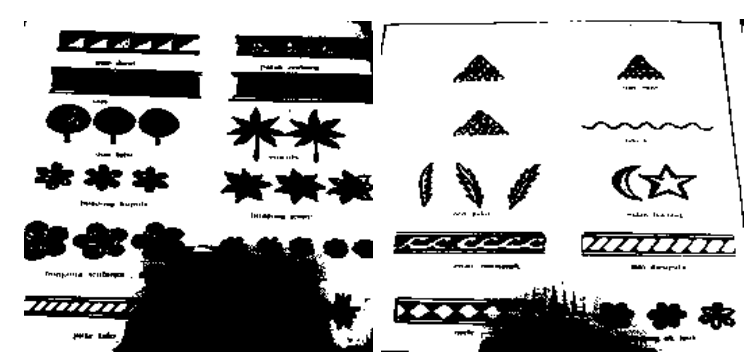

Gambar 1. Motif Dasar Kabupaten Aceh Besar Sumber: Dokumen Motif Hias Seni Ornamentik Aceh. Anonim: Hal: 3-4

Seperti dijelaskan sebelumnya, wilayah Aceh Utara, Pidie dan Aceh Timur memiliki motif dasar yang serupa namun di wilayah Aceh Utara muncul pula motif dasar yang banyak dipakai dan menjadi ciri. Motif tersebut adalah motif bungong matahari yang banyak diaplikasikan sebagai ragam hias ornamentik pada berbagai bidang baik kain, kayu maupun bidang lainnya. Berikut adalah motif tolak angin (ukiran pada atap rumah) dan pintu pada rumah dinas bupati Aceh Utara (Gambar 2, dan 3).
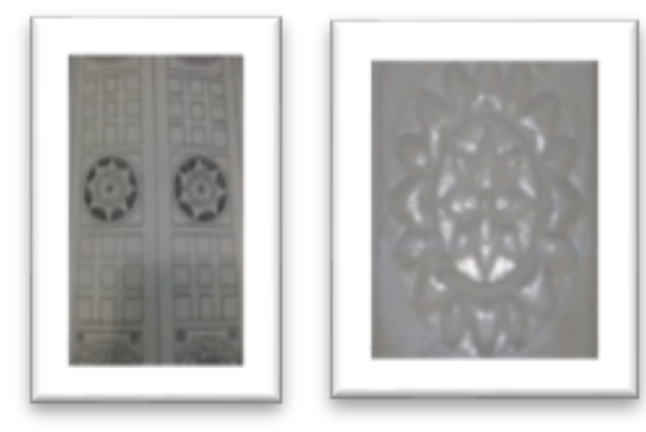

Gambar 2. Motif Pada Pintu Rumah Dinas Bupati Aceh Utara

Sumber: Kanan (__, Motif Hias Ornamentik Aceh; 52), Kiri (Dokumentasi Pribadi).

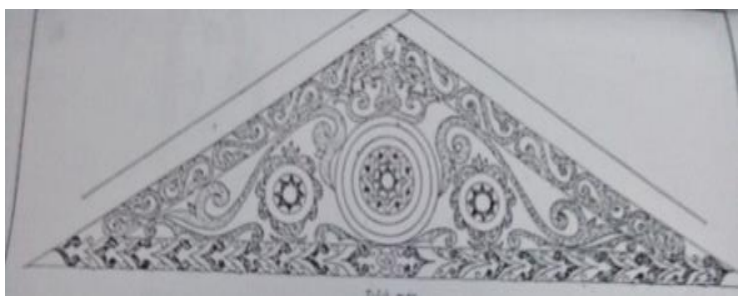

Gambar 3. Motif Tulak Angen (Tolak Angin) pada Atap Rumah Dinas Bupati Aceh Utara

Sumber: (__ Motif Hias Ornamentik Aceh; 56) 
Sedangkan untuk daerah Pidie dan Aceh besar, meskipun motif dasar lain juga diaplikasikan, namun motif dasar yang paling banyak muncul adalah motif dasar bulan yang dirangkai menjadi motif lain seperti awan meucanek, bungong keupula, daun (oun). motif ini banyak diaplikasikan sebagai ragam hias pada kasab yakni kerajinan dengan menggunakan sulam benang emas. Aceh besar dan pidie merupakandua daerah yang menjadi pusat atau sentra pengrajin kasab. Hasil kasab dapat berupa lapek duk (alas duduk), angkin (hiasan kelambu), kipah (kipas), tiree (tirai), langeh-langeh (langit-langit penghias plafon).

Rida Safuan Selian (2007) dalam jurnal Garuda dengan judul Kerajinan Sulaman Benang Emas 'Kasab Aceh" (Kajian Terhadap
Corak dan Fungsinya bagi Masyarakat Aceh) (portalgaruda.org.article.php, download 20 Agustus 2016 Pukul 21.00 WIB) menyebutkan bahwa motif-motif pada kasab biasanya menggunakan bentuk flora dan fauna yang telah distilisasi atau digubah, motif tersebut terdiri dari motif dasar yang telah disebutkan sebelumnya ditambah dengan motif sisek meuria (sisik buah rumbia), udeung (udang), motif merpati dan angsa. Namun pada saat ini motif fauna sudah sangat jarang ditemukan. Hal ini berdasarkan penelitian-penelitian sebelumnya disebabkan kuatnya pengaruh islam di wilayah pesisir Aceh (Nurcholish Majdid, 2013:127). Sedangkan kuatnya motif bulan pada kasab dapat dilihat pada Gambar 4.
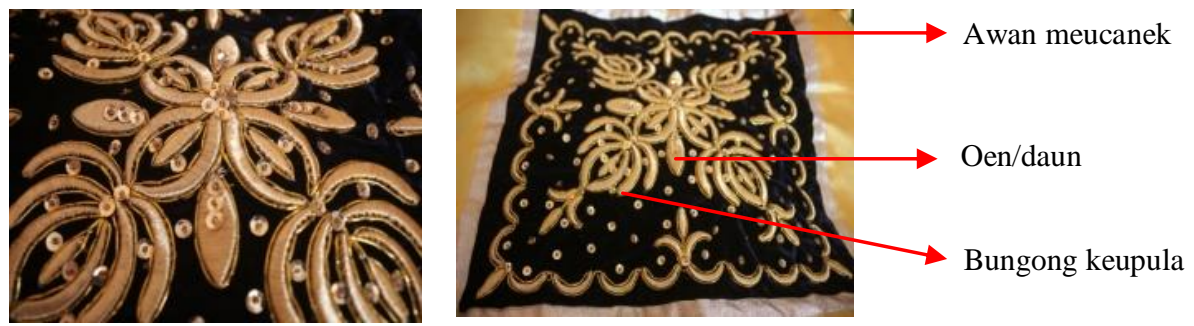

Gambar 4. Lapek Duk Khas Aceh Besar dan Pidie

Motif Dasar Aceh Besar menjadi dasar motif dasar di Aceh utara, pidie dan Aceh timur dengan ciri aplikasi yang membedakannya dengan wilayah lain. Cut Huzaimah seorang narasumber yang berkedudukan sebagai ketua bidang Putro Phang pada Majelis Adat Aceh Kota Langsa membenarkan pernyataan tersebut dengan menyebutkan bahwa daerah-daerah tersebut memiliki ciri yang hampir sama, khususnya untuk wilayah Aceh Timur. Pembedaan dari 3 wilayah besar ini adalah besaran atau ukuran motif dasar dan ada atau tidaknya garis tepi pada motif dasar tersebut.

Lebih lanjut narasumber membedakan 3 wilayah besar yang digolongkan dalam wilayah besar ragam hias Aceh dengan karakteristik pantai dan pedalaman dengan ciri masyarakat peladang (Wawancara $\mathrm{Hj}$. Cut Huzaimah, Tanggal 1 Juni 2016) yang terdiri dari:

1. Wilayah Pantai Utara, meliputi: Aceh Tamiang, Lhokseumawe, Kota Langsa, Beureuen, banda Aceh dan Sigli (ibu kota Pidie). Meskipun Sigli dikelompokkan dalam wilayah pantai utara namun memiliki gaya yang cukup mencolok dengan wilayah lainnya. Sedangkan wilayah dengan gaya ragam hias yang sangat identik dimiliki oleh 3 wilayah yakni Beureuen-Aceh Utara, Lhokseumawe dan Kota Langsa di Aceh Timur.

2. Wilayah Pantai Selatan, meliputi : Meulaboh (dalam pemetaan sebelumnya dapat dikelompokan pada Aceh Barat) dan Tapaktuan

3. Wilayah Pedalaman (ladang dan hutan) : Aceh Tenggara, Aceh Tengah dan Lokop (secara Administratif berada di Aceh Timur namun secara budaya merupakan sub budaya dari Gayo lues di Aceh Tenggara dan secara sejatah berasal dari Aceh Tengah).

Dalam kajian sejarah politik, pantai utara biasa disebut dengan pantai Timur (Sumatera) dan pantai selatan disebut dengan Pantai Barat (Sumatera). Dalam kajian ragam hias, khususnya pada pembuatan motif pada kain, pantai utara dan selatan dibedakan dalam bentuk sulaman dalam dan sulaman luar. Pada sulaman dalam, terdapat garis pembatas pinggir sebagai pola dasar, sedangkan di wilayah pantai selatan, 
sulaman tidak diberi batas pinggir yang menandai pola dasar.

Penamaan kelompok wilayah tersebut seringkali berbeda. Menurut pengelompokan sosial budaya, penyebaran penduduk di Daerah Istimewa Aceh dibagi dalam wilayah pantai utara dan timur, pantai barat dan selatan serta wilayah pedalaman di Aceh Tengah dan Tenggara. Persebaran penduduk diwilayah Aceh memang tidak merata. Pada umumnya penduduk itu lebih terpusatkan pada wilayahwilayah yang sudah terbuka walaupun potensi sumber dayanya relatif rendah. Lebih kurang dua pertiga penduduk bermukim pada dataran sepajang pantai utara dan timur. Sedangkan lainnya mendiami wilayah pantai barat dan selatan, serta pedalaman Aceh bagian tengah dan tenggara (Ibrahim Hasan, 1979; 5; Hariri Hadi, 1972: 24 dalam laporan depdikbud. 1983: 26).

Pada kajian ini, penulis menyimpulkan bahwa terdapat pengelompokan 3 wilayah besar dengan alasan mendasar bahwa pemetaan motif hias ornamnetik Aceh selaras, cocok, bersifat saling melengkapi dan bahkan menguatkan. Terutama dengan ditemukannya motif-motif dasar pada 7 wilayah Aceh. Pada wilayah barat dan selatan meskipun memiliki motif dasar masing-masing namun dapat dikatakan serumpun dengan penamaan yang hampir sama atau bentuk yang mirip dan munculnya motif penghubung yakni motif awan si oen (bentuk awan daun) (Gambar 5).

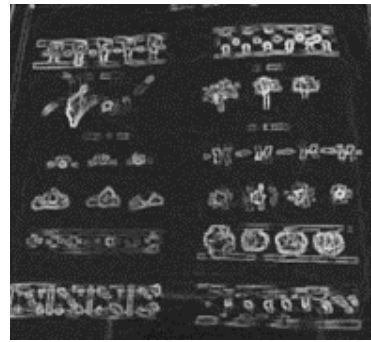

Motif Dasar Aceh Barat

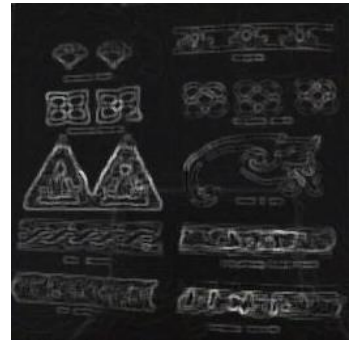

Motif Dasar Aceh Selatan

Gambar 5. Perbandingan Motif Dasar Aceh Barat dan Aceh Selatan Sumber: 2002. Motif Hias Ornamentik Aceh:91 dan 103)

Kedua motif dasar tersebut dihubungkan dengan bentuk motif awan si oen yang hampir mirip, bunga dan bunga kipas. Sedangkan motif dasar Aceh selatan yang berbeda dengan wilayah lain adalah munculnya motif buah delima atau boh geulima,bungong meutalo (talian bunga) dan bang-bang atau kupu-kupu serta pucuk rebung ornamentik berbentuk segitiga dengan isian motif dasar bunga. Pucuk rebung pada dasarnya merupakan motif yang dimiliki oleh hampir seluruh wilayah sumatera dengan pengaruh melayu yang kuat. Begitupula dengan Aceh, namun keberadaannya kemudian memiliki ciri khasnya tersendiri. Motif pucuk rebung di pesisir selatan Aceh merupakan motif yang lebih variatif dibandingkan dengan motif dasar pada wilayah yang berbatasan dengannya. Wilayah tersebut adalah wilayah Aceh Tengah. Pucuk rebung di tanah Gayo memiliki motif dasar yang sederhana berbentuk segitiga sebagai gambaran pucuk tuis atau pucuk bambu yang banyak ditemukan diwilayah tersebut. Selain memiliki makna kekayaan geografis, pucuk rebung di Aceh Tengah dan Aceh Tenggara memiliki makna sosial dan makna adat yang akan dijelaskan pada pembahasan berikutnya. Pucuk rebung sering diaplikasikan sebagai ragam hias pada tas atau kain bahkan kayu (Gambar 6).

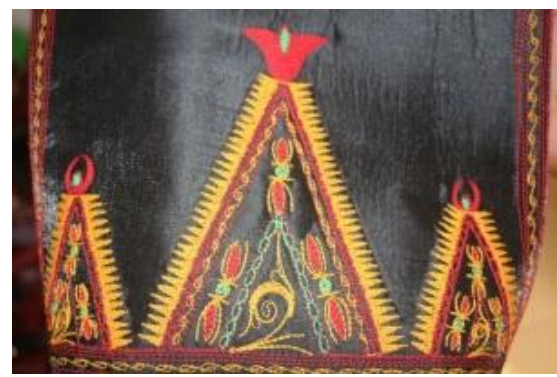

Gambar 6. Aplikasi Pucuk Rebung pada Tas Bordir

Motif Aceh Selatan memiliki keterkaitan dengan motif aceh Tengah termasuk pemanfaatan motif fauna. Namun bentuk fauna yang digunakan adalah udang, burung dan ikan, merupakan fauna khas daerah pesisir. 

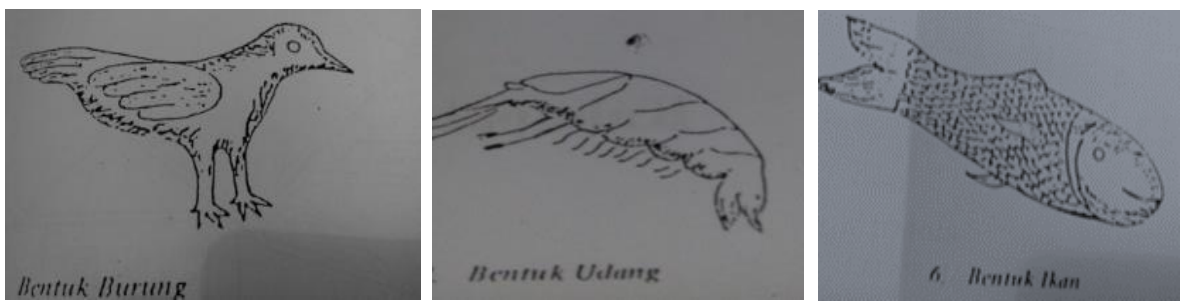

Gambar 7. Motif Bentuk Fauna Aceh Selatan

Sumber: 2002. Seni Hias Ornamentik Aceh: 112)

Motif Aceh Selatan bercirikan motif dengan ukuran yang besar dan memanfaatkan motif fauna meskipun sudah tidak banyak ditemukan (Gambar 8).
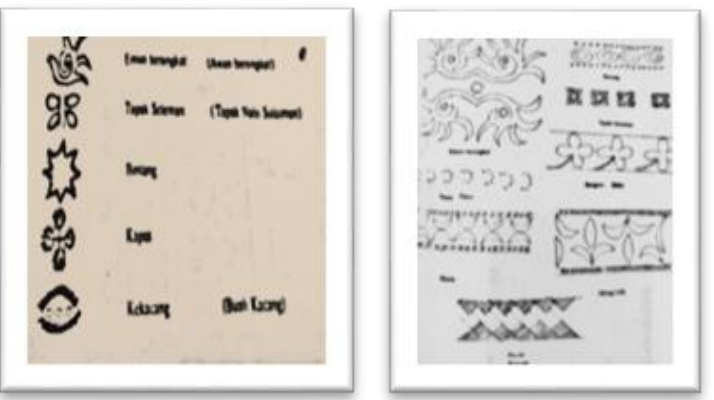

Gambar 8. Motif Dasar Aceh Tengah Sumber: ,Seni Hias Ornamentik Aceh; 76)

Aceh Tengah memiliki motif fauna berupa iken (ikan), naga, kur (ayam) (Gambar 9).

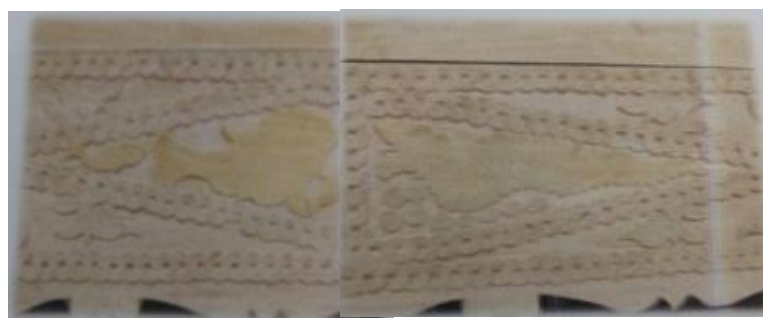

Gambr 9. Motif Fauna Aceh Tengah Gambar 9.

Motif dasar Aceh Tenggara seperti pada

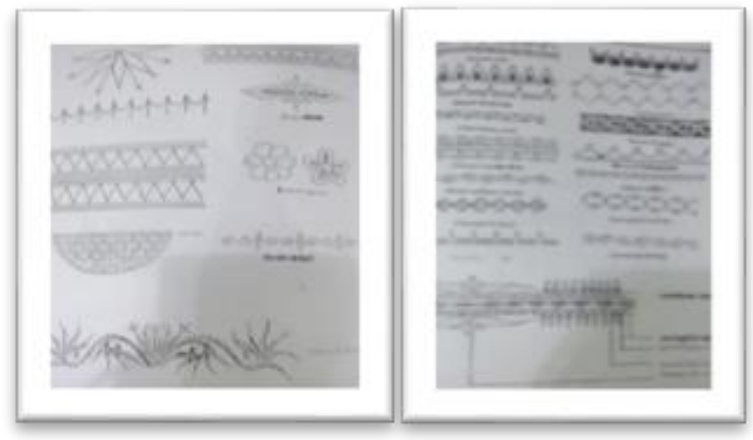

Gambar 9. Motif Dasar Aceh Tenggara
Sumber: 2002. Seni Hias Ornamentik Aceh: $115-116$

Pembahasan motif dasar pada pemetaan tersebut, menegaskan adanya sifat masyarakat Peladang dan Masyarakat Nelayan Aceh. Masyarakat Nelayan Aceh adalah masyarakat yang secara geografis tinggal di daerah pesisir atau pantai Aceh. Berdasarkan pembahasan sebelumnya wilayah pesisir Aceh dalam pembedaan ragam hiasnya dibedakan mencari ragam hias dengan karakteristik pantai Utara dan Pantai Selatan. Pantai Utara meliputi beberapa wilayah seperti Aceh Besar, Aceh Utara dan Aceh Timur. Sedangkan Pantai Selatan terdiri dari Aceh Selatan dan Barat. Wilayah Selatan sedikit terpengaruh oleh karakteristik ragam hias masyarakat Peladang di Aceh Tengah dan Tenggara yang disebabkan disparitas budaya.

Karakteristik ragam hias masyarakat nelayan di Aceh Utara banyak dipengaruhi oleh konsep ornamentik Islam yang kuat. Ragam Hias ornamentik Islam merupakan bentuk dengan basis kaligrafi dan arabesk. Kaligrafi dicurahkan untuk mengekspresikan ekuatan wakyu sedangkan arabesk merupakan pengemabangan rasa keindahan yang bebas dari mitos alam dan dilakukan dengan mengembangkan pola-pola abstrak yang diambil dari motif bunga-bungaan, daun-daun dan poligon-poligon. Poligonal merupakan bentuk datar yang terdiri dari garis lurus yang bergabung untuk membentuk rantai tertutup atau sirkuit. Pemanfaatan motif-motif tersebut disebabkan karena agama islam merupakan agama yang memiliki sikap anti ikonoklasme terutama anti gambar representasional yang bersifat simbolis dan emblematis apalagi yang bersifat magis (Nurcholish Madjid, 2013; 127).

Kaligrafi sebagai ragam hias muncul pada ukiran Mata uang Kerajaan Pasai sebagai kerajaan di pesisir Timur Aceh (pada pemetaan ragam hias ini berada di Pantai Utara). Uang dapat digolongkan sebagai peralatan dalam 
sistem ekonomi sebagai salah satu unsur budaya. Pada gambar pertama dibawah ini, mata uang tersebut terbuat dari emas dengan hiasan kaligrafi murni. Sedangkan pada gambar kedua memang muncul ikonoklasme yang bersifat magis berupa gambar ka'bah dan representasi raja dan rakyat yang seharusnya tidak boleh muncul karena bertentangan dengan semangat anti ikonoklasme, namun hal ini dapat dipahami sebab pada masa itu pengaruh budaya pra islam masih meninggalkan jejaknya di Aceh. Pada masa berikutnya (pasca berdirinya Aceh Darussalam) ikonoklasme tersebut telah tergeser.

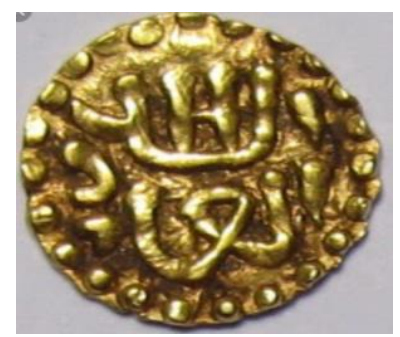

(a)

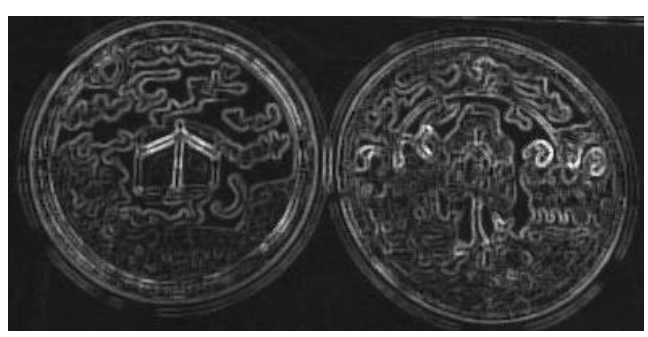

(b)

Gambar 10. Ragam Hias pada Mata Uang Samudra Pasai

Sumber: (a) http://www.help.kintamoney.com (b) ,2002 Motif Hias Seni Ornamentik Aceh; 50

Karakteristik ragam hias Arabesk berupa gubahan motif bunga-bungaan, daun-daun dan poligon dapat dicermati dari berbagai motif dasar yang muncul di wilayah Pantai Selatan Dan Pantai Utara Aceh. Motif poligon memiliki dasar sesegitiga. Adapun motif-motif yang dimaksud dijelaskan pada Tabel 1.

Tabel 1. Bentuk Ragam Hias Arabesk

\begin{tabular}{lll}
\hline $\begin{array}{c}\text { Motif Bunga- } \\
\text { Bungaan }\end{array}$ & $\begin{array}{c}\text { Motif Daun- } \\
\text { Daunan }\end{array}$ & $\begin{array}{c}\text { Motif } \\
\text { Poligonal }\end{array}$ \\
\hline $\begin{array}{l}\text { Bungong } \\
\text { keupula }\end{array}$ & Oun labu & Gigo daruet \\
$\begin{array}{l}\text { Bungong } \\
\text { Jeumpa }\end{array}$ & Oun ubi & Pucuk rebung \\
$\begin{array}{l}\text { Bungong } \\
\text { Seulanga }\end{array}$ & Oun paku & Puta talo \\
& &
\end{tabular}

Bungong Oun reudep Rante

Meulu

\begin{tabular}{lcc}
\hline \multicolumn{1}{l}{ Tabel 1. (Lanjutan) } \\
$\begin{array}{l}\text { Motif Bunga- } \\
\text { Bungaan }\end{array}$ & $\begin{array}{c}\text { Motif Daun- } \\
\text { Daunan }\end{array}$ & $\begin{array}{c}\text { Motif } \\
\text { Poligonal }\end{array}$ \\
\hline $\begin{array}{l}\text { Bungong ek } \\
\text { leuk }\end{array}$ & Oun murang & Bulan bintang \\
Bungong & & Talo meuputa \\
Kipah & & \\
Bungong & & \\
Mawo & & \\
\hline
\end{tabular}

Beberapa motif buah yang dijumpai anatara lain seperti buah nenas dan buah delima. Motif bunga, daun dan daun dapat dikelompokkan dalam ragam hias flora atau ragam hias naturalis. Pemanfaatan ragam hias ilmu ukur berupa poligonal tidak begitu menonjol.

Karakteristik masyarakat Peladang memiliki konsep pembagian ruang yang disebut dengan "pembagian tiga" atau "kesatuan tiga". Pembagian ini lebih menekankan independensi ruang dan egaliterian (Sumardjo, Jakob. 2002:20). Ragam hias yang sering muncul pada pola ruang kesatuan tiga adalah bidang kain dalam garis-garis pemisah. Garis "batas" yang bersifat dominan dan ada bidang "dalam" (bagian terluas bidang hias) dan bidang "luar: (disisi kiri dan kanan bidang utama). selain secara vertikal, garis sebagai ragam hias muncul pada bidang kategori horisontal, misalnya lambang lelaki, perempuan, lambang harmoni dan lambang kekuasaan. Pola dasar yang digunakan adalah bentuk-bentuk geometris. Pemaknaan terhadap ragam hias pada masyarakat Peladang banyak dihubungkan dengan penegakan adat dan etika sosial yang dipegang oleh masyarakat setempat. Hal yang unik adalah munculnya ragam hias sebagai representasi kekayaan geografis pada masingmasing wilayah. Ragam hias naturalis ini hanya sesekali muncul untuk menunjukan keistimewaan kekayaan sumber daya alam.

Berikut ini adalah motif dasar dan namanamanya yang merupakan ciri khas Aceh Tenggara dan Aceh Tengah sebagai varian dari ragam hias masyarakat peladang. 

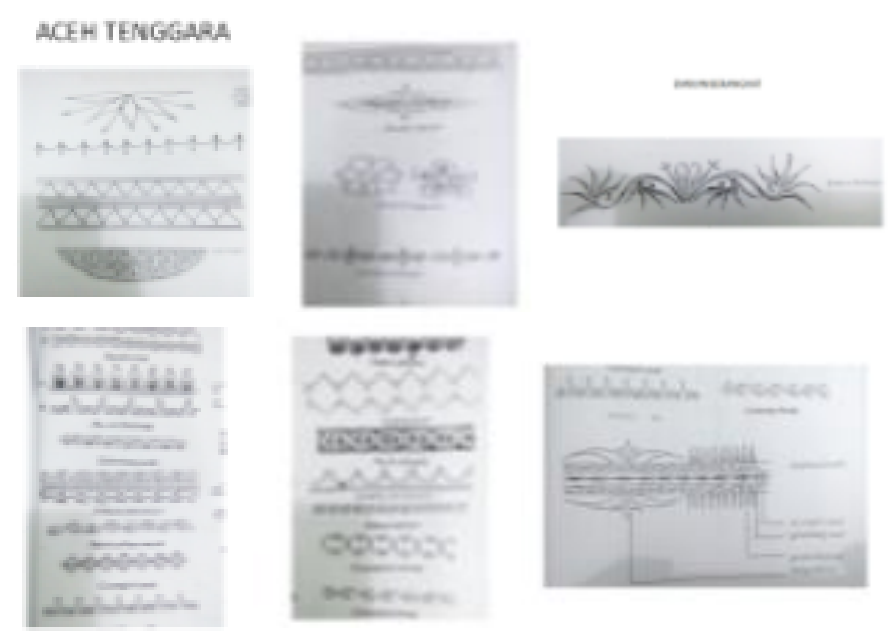

Gambar 11. Motif Dasar Aceh Tenggara Sumber: (_, 2002.Ragam Hias Ornamentik Aceh: 130)

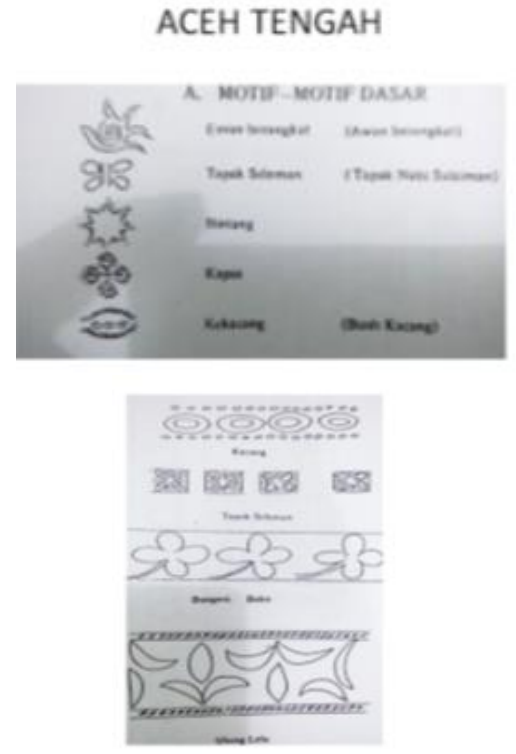

Gambar 12. Motif Dasar Aceh Tenggara Sumber: (__,2002.Ragam Hias Ornamentik Aceh: 142)

Tabel 2. Nama Motif di Aceh Tengah dan Tenggara

\begin{tabular}{c}
\hline Nama Motif \\
Pucuk khebung \\
Papan catur \\
Tikan jejak \\
Puter tali \\
Gelombang anak \\
Jejhak panthemken \\
Cecengkuk anak \\
Cuping gajah \\
Pakuk sekhpe \\
Lempang ketang \\
Bunge panah \\
Sesirung \\
Sarak opat
\end{tabular}

Layang-layangg Gegaping

\begin{tabular}{c}
\hline Tabel 2. (Lanjutan) \\
\hline Nama motif \\
\hline Selalu \\
Leladu \\
Tapak seleman \\
Rante \\
Ulung lela \\
Tapak tikus \\
Bungeni bako \\
Kacang \\
Kapas
\end{tabular}

Daerah dengan karakteristik masyarakat Peladang memiliki konsep pembagian ruang yang disebut dengan "pembagian tiga" atau "kesatuan tiga". Pembagian ini lebih menekankan independensi ruang dan egaliterian (Jakob ,Sumardjo. 2002:20). Ragam hias yang sering muncul pada pola ruang kesatuan tiga adalah bidang kain dalam garis-garis pemisah. Garis "batas" yang bersifat dominan dan ada bidang "dalam" (bagian terluas bidang hias) dan bidang "luar: (disisi kiri dan kanan bidang utama). selain secara vertikal, garis sebagai ragam hias muncul pada bidang kategori horisontal, misalnya lambang lelaki, perempuan, lambang harmoni dan lambang kekuasaan. Pola dasar yang digunakan adalah bentuk-bentuk geometris. Pemaknaan terhadap ragam hias pada masyarakat Peladang banyak dihubungkan dengan penegakan adat dan etika sosial yang dipegang oleh masyarakat setempat. Hal yang unik adalah munculnya ragam hias sebagai representasi kekayaan geografis pada masing- 
masing wilayah. Dari 2 wilayah budaya yang berbeda ini dapat ditemukan beberapa motif dasar yang sama dengan penamaan yang berbeda dan motif penghubung diantara keduanya.

Masyarakat Peladang Aceh secara budaya merupakan pengusung budaya gayo. Tanah Gayo dibagi menjadi 4 kelompok besar dengan wilayah yang dipisahkan oleh batas alam yang luas dan sulit untuk berhubungan satu sama lain, namun secara etnogarfis budaya gayo merupakan satu kesatuan (Hurgronje, 1997). 4 Kelompok tersebut adalah Gayo Lut dan gayo Deret yang mendiami Kabupaten Aceh tengah dan Bener Meriah, Gayo Lues di Aceh Tenggara dan terakhir adalah masyarakat Gayo yang dapat disebut Gayo rantau. Masyarakat Gayo rantau adalah minoritas di wilayah Aceh Timur yang disebut Gayo Lokop dan Gayo Kalul di wilayah Aceh Tamiang (Ibrahim,2007). Masyarakat Lokop sebagai sub Budaya Gayo dalam perspektif sejarah memiliki keterikatan asal dari kerajaan Lingge di Aceh Tengah, namun karena kedekatan Geografis dengan wilayah Aceh Tenggara, maka beberapa praktik budayanya cenderung mengikuti budaya gayo lues.

Keempat kelompok tersebut dalam ragam hiasnya secara umum dihubungkan dengan penggunaan elemen berupa garis, nada, struktur dan warna. Struktur yang digunakan adalah sulur, relung dan lingkaran. Warna yang menonjol adalah warna kuning, hijau, merah dan putih. Warna tersebut dipadu dalam warna dasar hitam yang bermakna tanah atau bumi. Warna kuning memiliki makna sebagai sifat musuket sipet (penuh pertimbangan) sebagi simbol raja atau pemimpin. Warna merah melambangkan sifat musidik sasat yaitu penuh keberanian dalam menegakan kebenaran. Warna putih melambangkan perlu sunet yakni kemampuan membedakan baik dan buruk serta kesucian. Warna hijau bermakna sebagai genap mupakat atau musyawarah (Ferawati, 2010. Portal Garuda.org/article.php, download tangal 25 Agustus 2016). Sedangkan bentuk motif yang memiliki sifat repetisi adalah emun berangkat, puthek tali atau puter tali, tapak seleman, pucuk ni tuis atau pucuk khebung/pucuk rebung dan motif peger dan ulen (bulan) yang merupakan simbol penerangan dan keindahan. Motif ulen merupakan susunan geometris dengan pola memancar.

\section{KESIMPULAN}

Sementara ini dapat ditarik suatu garis merah pada wilayah-wilayah pesisir Aceh bahwa ragam hias identitas pada masyarakat Nelayan identik dengan pengaruh Arabesk yang besar. Pengaruh ini menyebabkan dinamisnya ragam hias dalam bentuk stilirisasi bentuk agar semakin jauh dari bentuk aslinya. Selain itu, ragam hias tersebut jarang sekali memiliki makna khusus kecuali sebagai bentuk representasi alam namun bebas dari mitos-mitos yang dimaknakan secara magis. Hal ini dapat dipahami sebab, pesisir Aceh merupakan wilayah dengan pengaruh Islam yang lebih dominan dibandingkan wilayah pedalaman Aceh yang berbasis budaya peladang. Relevansi Islam dengan budaya dan khususnya seni sangat besar. Kondisi ini sesuai dengan pendapat Nurcholish Madjid (2013:127) yang menyatakan bahwa semangat egaliterianisme islam diwujudkan pula dalam sikapnya yang anti ikonoklasme, terutama anti gambar representasional yang bersifat emblemetis dan magis (yaitu setiap gambar yang mengungkapkan suatu mitologi kepada alam). Ide dasar dari sikap tersebut ialah bahwa magisme menghalangi manusia dari sifat keadilan berdasarkan persamaan (semangat egaliterianisme).

Untuk menghindari ikonoklasme, maka masyarakat nelayan seperti apa yang disarankan oleh peradaban Islam mengembangkan seni hias dalam bentuk kaligrafi dan arabesk. Kaligrafi mengekspresikan paham ketuhanan yan abstrak, tidak dapat dilukiskan kecuali melalui wakyuwahyu-Nya. Maka beberapa ragam hias pada masyarakat Nelayan Aceh juga mengkombinasikan kaligrafi tersebut. Sedangkan arabesk merupakan pengembangan rasa keindahan yang bebas dari mitos alam dan dilakukan dengan mengembangkan pola-pola abstrak yang diambil dari pengolahan motif bunga-bungaan, daun-daunan dan poligonpoligon.

Seni hias khas Islam berupa gubahan motif aksara Arab dan motif ilmu ukur yang digarap dalam hiasan bidang. Motif aksara Arab disusun dalam hiasan kaligrafi yang dipadukan dengan motif lain. Kaligragi Arab tampil sebagai hiasan pada mesjid, makam dan pada benda kerajinan. Ayat-ayat suci dari Al-Qur'an dengan indah sekali disusun menjadi hiasan batu 
nisan makam para raja, hulubalang dan para pembesar Aceh dengan keluarganya. Makammakam semacam ini tersebar di daerah Kotamadya Banda Aceh dan Samudra Pase. Bentuk batu nisannya adalah sangat khas untuk makam-makam di Aceh yang berbeda dengan batu nisan makam dari daerah lain (Album Seni Budaya Aceh. Depdikbud.1982:8).

Kekayaan ragam hias yang tampil memang tidak selalu bernafaskan Islam karena peranan tradisi seni hias asli yang masih terpelihara. Di antara motif-motif hias tradisional Aceh yang terkenal ialah motif stilasi binatang dan tumbuh-tumbuhan dan motif ilmu ukur. Termasuk jenis motif tumbuh-tumbuhan ialah motif bungong jeumpa (bunga cempaka), motif bungong meulue (bunga melur), motif pucuk rebung dan lain-lain.

Motif-motif hias tersebut juga tampil pada hiasan benda kerajinan anyaman, keramik, tenunan, sulaman, kerajinan bambu dan kayu. Untuk bahan baku kerajinan anyaman seringdipakai bambu, pandan dan mendong. Padaumumnya kerajinan anyaman termasuk kegiatan kaum wanita, khususnya para gadis;suatu kerajinan yang berdasarkan adat bahwa seorang gadis yang akan dipinang harus sudah mampu mengerjakan anyaman dengan hasilyang baik.

Hasil kerajinan anyaman antara lain berupa bermacam-macam tikar, tas dan wadah. Teknik anyaman daun pandan yang khas Aceh menghasilkan kerawangan dengan motif ilmu ukur seperti hiasan kerawang godok, lelayang, sesiku, putu talae, rantai, tapak catur, tapak kedidi dan sebagainya. Motif ilmu ukur juga tampil pada hasil kerajinan tenunan.

Daerah dengan karakteristik masyarakat Peladang memiliki konsep pembagian ruang yang disebut dengan "pembagian tiga" atau "kesatuan tiga". Pembagian ini lebih menekankan independensi ruang dan egaliterian (Sumardjo, Jakob. 2002:20). Ragam hias yang sering muncul pada pola ruang kesatuan tiga adalah bidang kain dalam garis-garis pemisah. Garis "batas" yang bersifat dominan dan ada bidang "dalam" (bagian terluas bidang hias) dan bidang "luar: (disisi kiri dan kanan bidang utama). selain secara vertikal, garis sebagai ragam hias muncul pada bidang kategori horisontal, misalnya lambang lelaki, perempuan, lambang harmoni dan lambang kekuasaan. Pola dasar yang digunakan adalah bentuk-bentuk geometris. Pemaknaan terhadap ragam hias pada masyarakat Peladang banyak dihubungkan dengan penegakan adat dan etika sosial yang dipegang oleh masyarakat setempat. Hal yang unik adalah munculnya ragam hias sebagai representasi kekayaan geografis pada masingmasing wilayah. Dari 2 wilayah budaya yang berbeda ini dapat ditemukan beberapa motif dasar yang sama dengan penamaan yang berbeda dan motif penghubung diantara keduanya.

Melalui penelitian ini dapat ditarik suatu garis merah pada wilayah-wilayah pesisir Aceh bahwa ragam hias identitas pada masyarakat Nelayan identik dengan pengaruh Arabesk yang besar. Pengaruh ini menyebabkan dinamisnya ragam hias dalam bentuk stilirisasi bentuk agar semakin jauh dari bentuk aslinya. Selain itu, ragam hias tersebut jarang sekali memiliki makna khusus kecuali sebagai bentuk representasi alam namun bebas dari mitos-mitos yang dimaknakan secara magis. Hal ini dapat dipahami sebab, pesisir Aceh merupakan wilayah dengan pengaruh Islam yang lebih dominan dibandingkan wilayah pedalaman Aceh yang berbasis budaya peladang. Relevansi Islam dengan budaya dan khususnya seni sangat besar. Kondisi ini sesuai dengan pendapat Nurcholish Madjid (2013:127) yang menyatakan bahwa semangat egaliterianisme islam diwujudkan pula dalam sikapnya yang anti ikonoklasme, terutama anti gambar representasional yang bersifat emblemetis dan magis (yaitu setiap gambar yang mengungkapkan suatu mitologi kepada alam). Ide dasar dari sikap tersebut ialah bahwa magisme menghalangi manusia dari sifat keadilan berdasarkan persamaan (semangat egaliterianisme).

Untuk menghindari ikonoklasme, maka masyarakat nelayan seperti apa yang disarankan oleh peradaban Islam mengembangkan seni hias dalam bentuk kaligrafi dan arabesk. Kaligrafi mengekspresikan paham ketuhanan yan abstrak, tidak dapat dilukiskan kecuali melalui wakyuwahyu-Nya. Maka beberapa ragam hias pada masyarakat Nelayan Aceh juga mengkombinasikan kaligrafi tersebut. Sedangkan arabesk merupakan pengembangan rasa keindahan yang bebas dari mitos alam dan dilakukan dengan mengembangkan pola-pola abstrak yang diambil dari pengolahan motif bunga-bungaan, daun-daunan dan poligonpoligon. 
Seni hias khas Islam berupa gubahan motif aksara Arab dan motif ilmu ukur yang digarap dalam hiasan bidang. Motif aksara Arab disusun dalam hiasan kaligrafi yang dipadukan dengan motif lain. Kaligragi Arab tampil sebagai hiasan pada mesjid, makam dan pada benda kerajinan. Ayat-ayat suci dari Al-Qur'an dengan indah sekali disusun menjadi hiasan batu nisan makam para raja, hulubalang dan para pembesar Aceh dengan keluarganya. Makammakam semacam ini tersebar di daerah Kotamadya Banda Aceh dan Samudra Pase. Bentuk batu nisannya adalah sangat khas untuk makam-makam di Aceh yang berbeda dengan batu nisan makam dari daerah lain (Proyek Media Kebudayaa. Album Seni Budaya Aceh. Depdikbud.1982:8).

Kekayaan ragam hias yang tampil memang tidak selalu bernafaskan Islam karena peranan tradisi seni hias asli yang masih terpelihara. Di antara motif-motif hias tradisional Aceh yang terkenal ialah motif stilasi binatang dan tumbuh-tumbuhan dan motif ilmu ukur. Termasuk jenis motif tumbuh-tumbuhan ialah motif bungong jeumpa (bunga cempaka), motif bungong meulue (bunga melur), motif pucuk rebung dan lain-lain.

Motif-motif hias tersebut juga tampil pada hiasan benda kerajinan anyaman, keramik, tenunan, sulaman, kerajinan bambu dan kayu. Untuk bahan baku kerajinan anyaman seringdipakai bambu, pandan dan mendong. Padaumumnya kerajinan anyaman termasuk kegiatan kaum wanita, khususnya para gadis;suatu kerajinan yang berdasarkan adat bahwa seorang gadis yang akan dipinang harus sudahmampu mengerjakan anyaman dengan hasilyang baik.

Hasil kerajinan anyaman antara lain berupa bermacam-macam tikar, tas dan wadah. Teknik anyaman daun pandan yang khas Aceh menghasilkan kerawangan dengan motif ilmu ukur seperti hiasan kerawang godok, lelayang, sesiku, putu talae, rantai, tapak catur, tapak kedidi dan sebagainya. Motif ilmu ukur juga tampil pada hasil kerajinan tenunan.

Daerah dengan karakteristik masyarakat Peladang memiliki konsep pembagian ruang yang disebut dengan "pembagian tiga" atau "kesatuan tiga". Pembagian ini lebih menekankan independensi ruang dan egaliterian (Sumardjo, Jakob. 2002:20). Ragam hias yang sering muncul pada pola ruang kesatuan tiga adalah bidang kain dalam garis-garis pemisah. Garis "batas" yang bersifat dominan dan ada bidang "dalam" (bagian terluas bidang hias) dan bidang "luar: (disisi kiri dan kanan bidang utama). selain secara vertikal, garis sebagai ragam hias muncul pada bidang kategori horisontal, misalnya lambang lelaki, perempuan, lambang harmoni dan lambang kekuasaan. Pola dasar yang digunakan adalah bentuk-bentuk geometris. Pemaknaan terhadap ragam hias pada masyarakat Peladang banyak dihubungkan dengan penegakan adat dan etika sosial yang dipegang oleh masyarakat setempat. Hal yang unik adalah munculnya ragam hias sebagai representasi kekayaan geografis pada masing masing wilayah. Dari 2 wilayah budaya yang berbeda ini dapat ditemukan beberapa motif dasar yang sama dengan penamaan yang berbeda dan motif penghubung diantara keduanya.

\section{Daftar Pustaka}

Anonim (2002) Motif Hias Seni Ornamentik Aceh. Dokumen diperoleh dari informan di Ulle Madoon, Aceh Utara

Creswell (2012) Education Research, planning, conducting and evaluation quantitative and qualitative Research. 4Th Edition. Boston: Pearson

Hasanudin, Basri (1985) "Beberapa Hal Mengenai Struktur Ekonomi Masyarakat Pantai", dalam A.S. Achmad dan S.S. Acip (Peny.). Komunikasi dan Pembangunan. Jakarta: Penerbit Sinar Harapan

Hurgronje (1997) Aceh, Rakyat dan Adat Istiadatnya, jil. 1 (terj.) Sutan Meimoen. Jakarta: Inis

Ibrahim Hasan (1979) Hariri Hadi, 1972: 24. dalam laporan depdikbud. 1983 Proyek Inventarisasi Dan Dokumentasi Kebudayaan Daerah Departemen Pendidikan Dan Kebudayaan . 1983. Aspek Geografi Budaya Dalam Wilayah Pembangunan Daerah Istimewa Aceh. Jakarta: Debdikbud.

Jakob, Sumardjo (2002) Arkeologi Budaya Indonesia. Yogyakarta: Qalam. 
Marsden, William (2008) Sejarah Sumatra. Jakarta: Komunitas Bambu.

Nurcholish, Madjid (2013) Islam Kemoderenan dan Keindonesiaan. Edisi ke 2. Bandung: Mizan

Proyek Media Kebudayaan Departemen Pendidikan dan Kebudayaan Direktorat Jenderal Pendidikan. 1982/1983. Album Seni Budaya Aceh. Jakarta: Debdikbud

Reid, Anthony (2011) Menuju Sejarah Sumatra: Antara Indonesia dan Dunia. Jakarta: Yayasan Pustaka Obor Indonesia: KITLV Jakarta.

Rida, Safuan Selian (2007) Kerajinan Sulaman Benang Emas 'Kasab Aceh" (Kajian Terhadap Corak dan Fungsinya bagi Masyarakat Aceh) (portalgaruda.org.article.php, download 20 Agustus 2016.Pukul $21.00 \mathrm{WIB})$.

Spradley (2007) Metode Etnografi. Yogyakarta: tiara Wacana.

Sunaryo, A.,dkk. (2009) Bentuk dan Pola Ornamen pada Candi Kalasan dan Prambanan. Laporan Penelitian DIPA Unnes Tahun Anggaran 2009 no.061.0/023-04.2/XIII/2009.FBS.

Universitas Negeri Semarang.

\section{Sumber wawancara}

Hj. Cut Huzaimah, Tanggal 1 Juni 2016, pukul $13.00-15.30$ WIB.

Ibu Susi, Pengurus Dekranasda Kota Lhokseumawe, 2 Juni 2016, Pukul $11.30-14.00$ WIB.

Ibu Mariana, pengrajin tas bordir ulee Madoon, Aceh Utara, 3 Juni 2016, Pukul 15.0018.00 WIB

\section{Sumber Gambar}

http://www.help.kintamoney.com 